\title{
Paper
}

Int'l J. of Aeronautical \& Space Sci. 16(2), 311-324 (2015)

DOI: http://dx.doi.org/10.5139/IJASS.2015.16.2.311

\section{Drag Reduction Design for a Long-endurance Electric Powered UAV}

\author{
Wonjin Jin* \\ Dept. of Aviation Maintenance Engineering, Far East University, Chungbuk 369-700, Korea
}

\section{Yung-Gyo Lee**}

Aerodynamics Division, Korea Aerospace Research Institute, Daejeon 305-333, Korea

\begin{abstract}
This study presents computational analyses for low-drag aerodynamic design that are applied to modify a long-endurance UAV. EAV-2 is a test-bed for a hybrid electric power system (fuel cell and solar cell) that was developed by the Korean Aerospace Research Institute (KARI) for use in future long-endurance UAVs. The computational investigation focuses on designing a wing with a reduced drag since this is the main contributor of the aerodynamic drag. The airfoil and wing aspect ratio of the least drag are defined, the fuselage configuration is modified, and raked wingtips are implemented to further reduce the profile and induced drag of EAV-2. The results indicate that the total drag was reduced by $54 \%$ relative to EAV-1, which was a small-sized version that was previously developed. In addition, static stabilities can be achieved in the longitudinal and lateral-directional by this low-drag configuration. A long-endurance flight test of 22 hours proves that the low-drag design for EAV-2 is effective and that the average power consumption is lower than the objective cruise power of 200 Watts.
\end{abstract}

Key words: Long Endurance, UAV, CFD, Low-Reynolds Airfoil, Drag Prediction

\section{Nomenclature}

$\begin{array}{ll}A & =\text { Area, } \mathrm{m}^{2} \\ A R & =\text { Aspect ratio, } \sim \\ b_{W} & =\text { Wing span, } m \\ C_{r} & =\text { Chord length of airfoil root, } m \\ c_{d} & =\text { Drag coeff. of airfoil, } \sim \\ c_{d_{\min }} & =\text { Minimum drag coefficient of airfoil, } \sim \\ c_{d @ c l=1} & =\text { Drag coeff. of airfoil at } c_{l}=1.0, \sim \\ C_{D} & =\text { Drag coeff. of aircraft, } \sim \\ C_{D_{\min }} & =\text { Minimum drag coefficient of aircraft, } \sim \\ C_{D @ C L=1} & =\text { Drag coeff. of aircraft at } C_{L}=1.0, \sim \\ c . g . & =\text { Center of gravity, } \% \\ c_{l} & =\text { Lift coeff. of airfoil, } \sim \\ c_{l_{\alpha}} & =\text { Lift curve slope of airfoil, } \text { rad }^{-1} \\ c_{l_{\max }} & =\text { Maximum lift coeff. of airfoil, } \sim \\ C_{L} & =\text { Lift coeff. of aircraft, } \sim \\ C_{L_{\max }} & =\text { Maximum lift coeff. of aircraft, } \sim\end{array}$

$C_{L_{\alpha}} \quad=$ Lift curve slope of aircraft, rad $^{-1}$

$C_{l p} \quad=$ Rolling moment coeff. with change of roll rate, $\mathrm{rad}^{-1}$

$C_{l r} \quad=$ Rolling moment coeff. with change of yaw rate, $\mathrm{rad}^{-1}$

$C_{l_{\beta}} \quad=$ Rolling moment coeff. with sideslip angle, $\mathrm{rad}^{-1}$

$C_{m_{a}} \quad=$ Pitching moment coeff. of aircraft with angle of attack, $\mathrm{rad}^{-1}$

$C_{m_{\dot{\alpha}}} \quad=$ Pitching moment coeff. with change of angle of attack, $\mathrm{rad}^{-1}$

$C_{m_{q}} \quad=$ Pitching moment coeff. of aircraft with pitch rate, $\mathrm{rad}^{-1}$

$C_{n_{q}} \quad=$ Yawing moment coeff. with change of roll rate, $\mathrm{rad}^{-1}$

$C_{n_{r}} \quad=$ Yawing moment coeff. with change of yaw rate, $\mathrm{rad}^{-1}$

$C_{n_{\beta}} \quad=$ Yawing moment coeff. with sideslip angle, $\operatorname{rad}^{-1}$
This is an Open Access article distributed under the terms of the Creative Commons Attribution Non-Commercial License (http://creativecommons.org/licenses/by$\mathrm{nc} / 3.0 /$ which permits unrestricted non-commercial use, distribution, and reproduction in any medium, provided the original work is properly cited. (c) * Assistant Professor, Corresponding author: jwonjin@gmail.com

** Principal Researcher, lyg@kari.re.kr 


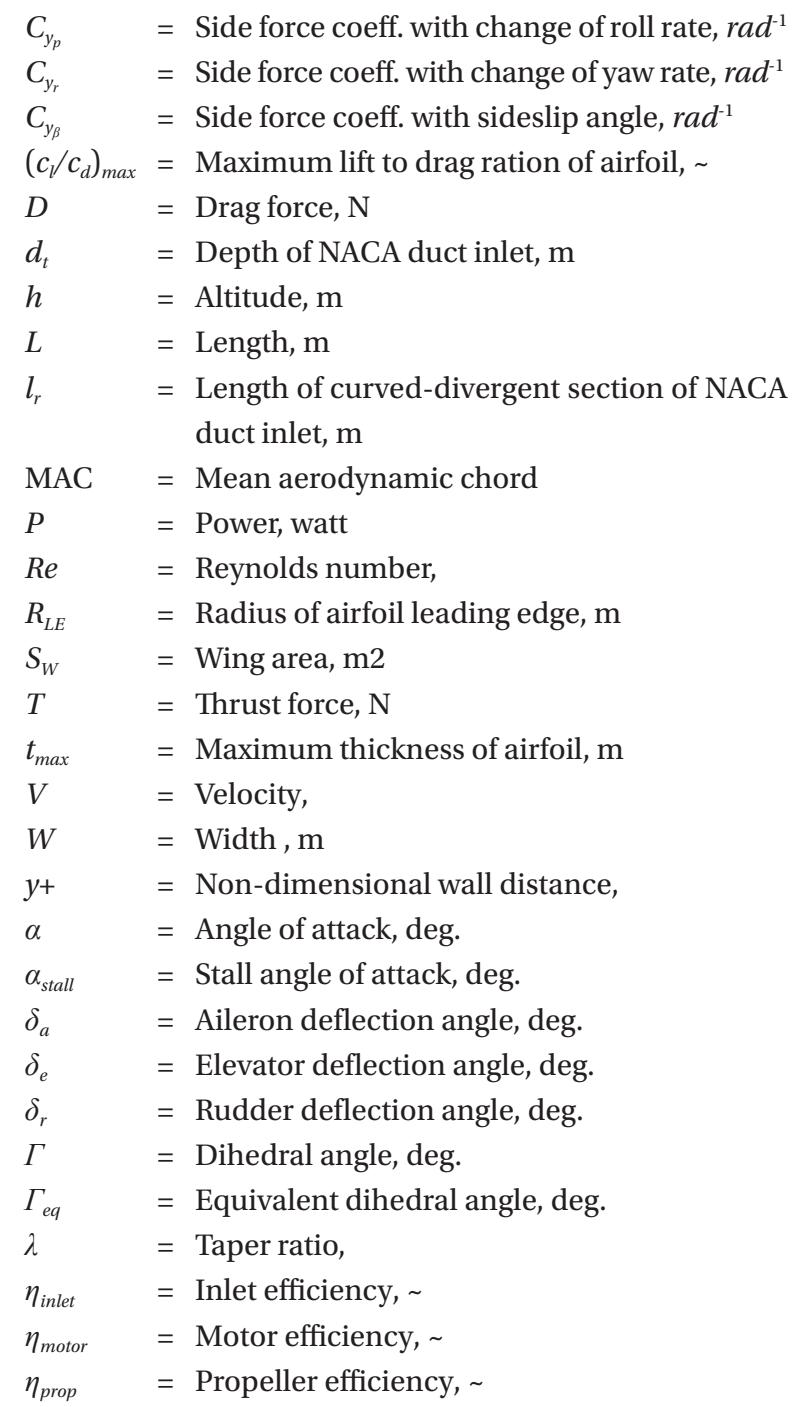

\section{Introduction}

Recent environmental issues have drawn a considerable amount of attention to the use of eco-friendly or renewable power sources, such as solar/wind energy or fuel cell energy, and in particular, there has been a rising interest on using renewable sources of energy to power aircraft systems. Solar energy is considered to be an appropriate power source for long-endurance flights since electricity can be recharged from solar cells during daytime flight to power the aircraft during nighttime. In 2010, Zephyr, a solar-powered UAV, set the world endurance flight record of 336 hours (2 weeks) and showed the possibility of eternal flight. ${ }^{1}$ Solar Impulse, ${ }^{2}$ a solar-powered manned aircraft, is planning to make the first aerial circumnavigation of the world in 2015. The technologies acquired from these experimental aircraft will contribute to the development of unmanned aircraft intended for long-endurance flight at a high altitude. High Altitude Long Endurance (HALE) UAVs are considered to be future air vehicle systems that can provide functionality similar to that of satellites, with relatively low operation and maintenance costs.

The Korea Aerospace Research Institute (KARI) has also studied renewable power systems and highly-effective aircraft configurations for use in future long-endurance UAV systems. Hybrid power systems ${ }^{3,4}$ that implement both solar and fuel cell energy sources are one of the KARI's research goals. Fuel cells are known to have a higher energy density than ordinary batteries, and KARI tested hydrogen-fuel cell power system in EAV-1, which is driven by a small propeller $\left(L=1.7 \mathrm{~m}\right.$ and $\left.S_{w}=0.68 \mathrm{~m} 2\right){ }^{5,6}$ EAV-2 is a larger UAV $(L \approx 3.0$ $\mathrm{m}$ and $S_{w} \approx 2.0 \mathrm{~m}^{2}$ ) that is planned to have a heavier hybrid power system with wider wings that can accommodate the installation of mono-crystalline silicon solar cells. In-flight power consumption should be minimized to carry out longendurance flight, and the performance objectives of EAV-2 are to conduct cruise flight that continues for more than 20 hours with an average consumption of less than 200 Watts. The power required for an aircraft during flight is directly proportional to the total drag that the aircraft generates. Therefore, the design should incorporate low-drag modifications in order for EAV-2 to achieve its performance objectives.

In a low-speed regime, the profile drag and the induced

Table 1. Drag coefficients of aircraft component (EAV-2b, FLUENT)

\begin{tabular}{c|cccc}
\hline $\begin{array}{c}\text { Aircraft } \\
\text { Parts }\end{array}$ & $\begin{array}{c}\text { Pressure } \\
\text { Drag }\end{array}$ & $\begin{array}{c}\text { Viscous } \\
\text { Drag }\end{array}$ & $\begin{array}{c}\text { Total } \\
\text { Drag }\end{array}$ & $\begin{array}{c}\text { Percentage } \\
(\%)\end{array}$ \\
\hline Fuselage & 0.00192 & 0.00212 & 0.00404 & 9.8 \\
$\begin{array}{c}\text { Horizontal } \\
\text { stabilizer } \\
\text { Vertical }\end{array}$ & 0.00012 & 0.00091 & 0.00123 & 3.0 \\
$\begin{array}{c}\text { stabilizer } \\
\text { Wing }\end{array}$ & 0.00012 & 0.00063 & 0.00075 & 1.8 \\
\hline \multicolumn{5}{r}{} \\
\hline
\end{tabular}


drag are dominant for aircraft, and most of the drag is produced at the wings. A CFD analysis of a candidate configuration for EAV-2 with a large, high aspect ratio for the wings suggests that wings generate $85.4 \%$ of the total aircraft drag, as seen in Table 1. Therefore, this study conducts a computational investigation to reduce drag by optimizing many parameters of wing design, including high-lift lowdrag airfoils, wing aspect ratio, and wingtip device to induce a low amount of drag. Table 1 shows that the fuselage is the component that generates the next largest amount of drag. Therefore, CFD analysis is used to evaluate three different fuselage configurations in order to obtain the fuselage with the least amount of drag. In addition, the NACA duct inlet of the minimum-drag profile is considered for EAV-2, and an analysis of longitudinal and lateral-directional stabilities is carried out to produce the final configuration. A flight lasting for 22 hours was conducted to determine the results of the drag minimization.

\section{Computational Methodologies}

\subsection{Computational code and setup procedures}

In this study, we used XFOIL to analyze the aerodynamic characteristics of low-Reynolds airfoils. ${ }^{7}$ XFOIL is a simple, easily-accessible software package that can be used for airfoil design in a low-speed regime. Wind tunnel tests were carried out to capture experimental data for the airfoil, ${ }^{8,9}$ and the results of the XFOIL prediction were validated for two airfoils with a low-Reynolds number (SD7032 and SG6043), as shown in Fig. 1. The comparison in the figure suggests that the aerodynamic performance calculated by XFOIL is quite consistent with that obtained from the wind tunnel. Therefore, the predictions obtained from XFOIL, which is a panel method code for use with simplified viscous models, is suitable to evaluate the performance of an airfoil.

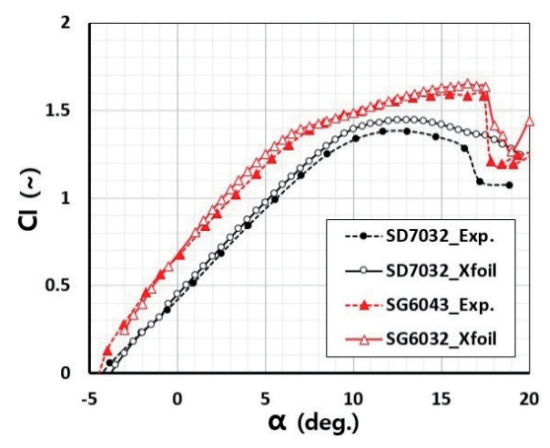

(a) Lift curve slop
The computational analyses were carried out using FLUENT, a commercial CFD software package. ${ }^{10}$ GAMBIT $^{11}$ and T-GRID ${ }^{12}$ were respectively used as pre-processing tools for surface and volume mesh generation. The non-dimensional wall distance was defined as $y+<5$ to obtain a proper nearwall mesh resolution, and the height of the first mesh cell from the surface was defined as $2 \times 10^{-4} \mathrm{~m}$ based on a cruise speed of $V=12 \mathrm{~m} / \mathrm{s}$ for EAV-2. A total of 12 mesh-layers were constructed within the boundary layer to simulate the viscous effects over the surfaces of the aircraft, and the total size for the structured and unstructured meshes was of approximately 20 million cells. Fig. 2 (a) presents an example of surface meshing that was studied for the EAV-2 configuration and a fan disk. The boundary conditions for the velocity at the inlet and the pressure at outlet were applied to the C-type far-field domain shape, as shown in Fig. 2 (b). The mean geometric chord length of the wing indicated that the Reynolds number of the free-stream flow was $R e=2.8 \times 10^{5}$. We used the Spalart-Allmaras turbulence model, which is quite popular for various technical uses given its reliability and quick calculation. The turbulent intensity and turbulent length scale were set to $0.1 \%$ and $0.01 \mathrm{~m}$, respectively based on the turbulence level of the Low Speed Wind Tunnel at KARI. The calculations were than carried out for the lift, drag, and pitching moment, and the system was monitored until the value of each coefficient changed by less than $0.5 \%$. The parallel computing systems in the Aerodynamics Division Lab at KARI were utilized to conduct the simulations and computations.

\subsection{Fan disk model}

EAV-2 is a propeller-driven aircraft that experiences a slipstream effect. This slipstream effect can change the friction and pressure drag over the surface of the aircraft. Therefore, the rotating propeller is also simulated to ensure that the total drag of EAV-2 is properly estimated. The fan

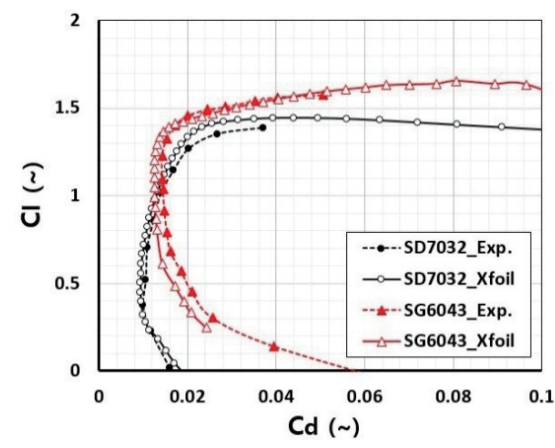

(b) Drag polar

Fig. 1. Verification of XFOIL results with experimental data ${ }^{8,9}\left(R e=2.0 \times 10^{5}\right)$ 
disk model was implemented as a boundary condition in FLUENT to simulate the effect of the propeller. A fan disk was modeled at the position of the propeller, as shown in Fig. 2(a), and the fan boundary condition was applied to the disk domain. The pressure distribution on the fan disk was defined according to the typical radial pressure distribution of a two-blade propeller. The maximum pressure occurred at $r / R=0.75$, and the accumulated pressure jump over $r / R=0.5$ was $80 \%$ of the total pressure jump of the disk. No pressure jump was assumed for $r / R=0.15$ due to the diameter of the aircraft nose at the propeller location. The thrust angle was defined as $2^{\circ}$, and the induced tangential velocity was calculated using performance charts for a two-bladed propeller. $^{13}$ The input parameters for the EAV-1 and EAV-2 fan disk model are presented in Table 2, and the results of the slipstream simulation for EAV-2 are shown in Fig. 3.

The results of the CFD analysis were validated using flight test data obtained for EAV- $1 .{ }^{6}$ Fig. 4 presents a comparison the results from FLUENT and the flight test in terms of the aerodynamic performance of EAV-1 at the same speed and Reynolds number. In a cruise condition at $\alpha=5.6^{\circ}$ and $C_{L}=0.78$, the time-averaged in-flight drag was $C_{D}=0.0736$. However, the CFD analysis produces $C_{D}=0.0533$, which is substantially under-predicated by $27.6 \%$. The discrepancy is reduced to $14.4 \%$ when the additional drag from the propeller slipstream is more properly predicted by applying the fan-disk model $\left(C_{D}=0.0630\right)$, as shown in Fig. 4 . A discrepancy of $14.4 \%$ is still significant and is mainly due a result of the differences in the

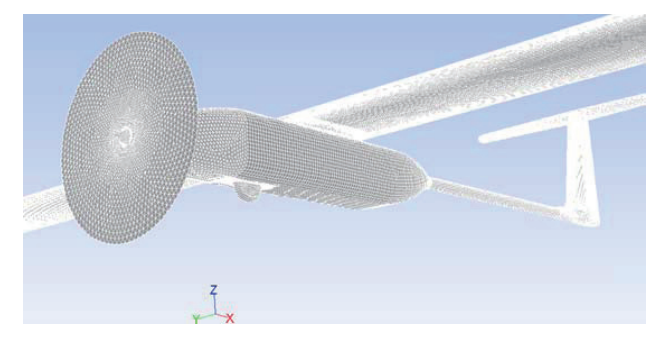

(a) Surface meshing for EAV-2 with fan disk

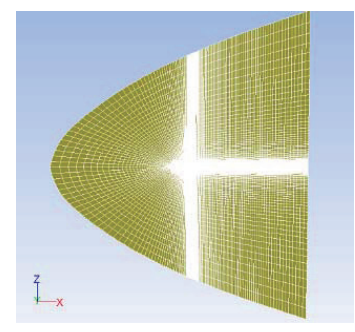

(b) C-type far-field domain

Fig. 2. Mesh generation for CFD analysis

Table 2. Input parameters for fan disk model

\begin{tabular}{ccc}
\hline Inputs & EAV-1 & EAV-2a/b/c \\
\hline $\begin{array}{c}\text { Fan disk } \\
\text { Diameter }(\mathrm{m})\end{array}$ & 0.356 & 0.508 \\
Total thrust $(\mathrm{N})$ & 5.9 & 10.0 \\
$\begin{array}{c}\text { Total pressure } \\
\text { jump }(\mathrm{Pa})\end{array}$ & 61 & 50 \\
$\begin{array}{c}\text { Induced velocity } \\
(\mathrm{m} / \mathrm{s})\end{array}$ & 5.93 & 3.62 \\
\hline
\end{tabular}

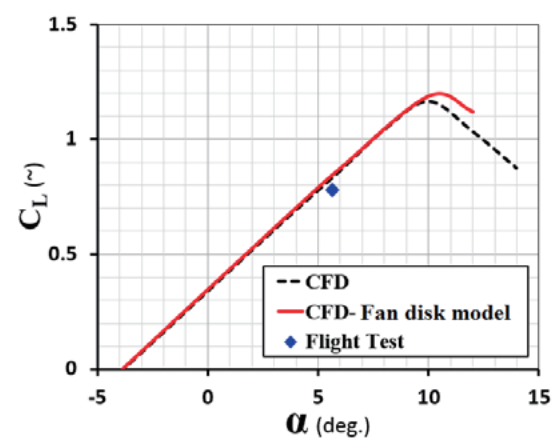

(a) Lift curve slop

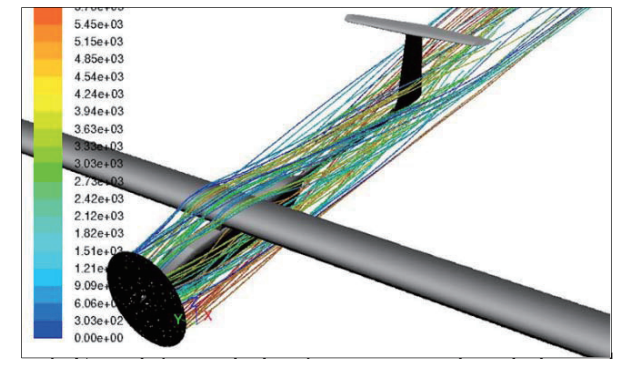

Fig. 3. Simulation of slipstream using fan disk model

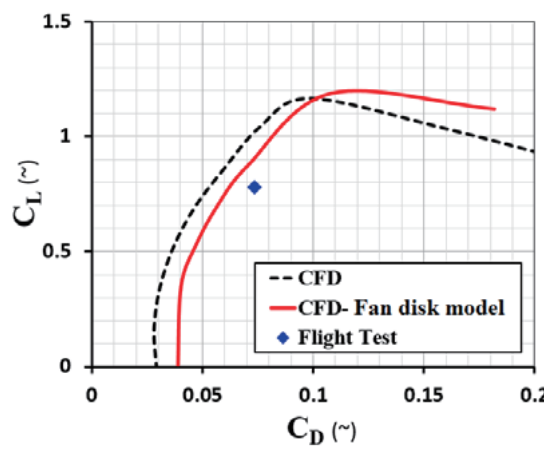

(b) Drag polar

Fig. 4. Validation of CFD analysis for EAV-1 aerodynamic performance with flight test data6 (FLUENT, $R e=2.8 \times 10^{5}$ ) 
flight condition. Actual flight involves steady-level turning flight for long-endurance tests, but a steady-level flight is assumed in the CFD analysis. Therefore, the discrepancy is further reduced to $2.3 \%$ after considering the additional drag from the aircraft trim and load factor for the turning flight, as calculated by the aircraft design software, AAA. ${ }^{14}$

\section{Results and Discussion}

\subsection{Wing design for drag reduction}

\subsubsection{Low-Reynolds number airfoil}

It is critical to minimize drag at cruise condition for longendurance EAV-2 flights. Therefore, careful consideration and analysis should be applied to design or select an airfoil with the least drag. In this study, we defined the target lift coefficient of the airfoil at cruise as $c_{l}=1.0$ based on the design and performance parameters of EAV-2, such as a wing area of $S_{W} \approx 2.0 \mathrm{~m}^{2}$ and cruise speed of $V \approx 12 \mathrm{~m} / \mathrm{s}$. Considering the low cruise speed and low air-density at a high altitude, the airfoil performance in the low-Reynolds number regime should be thoroughly assessed. Therefore, the aerodynamic characteristics of six typical low-Reynolds number airfoils, including SD7032M, SG6043, FX63-137, S1223, E61, and GOE15, was computationally investigated. SD7032M was

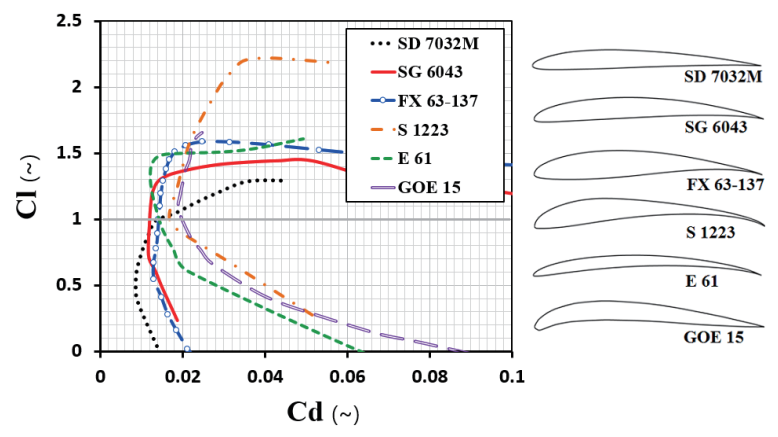

Fig. 5. Drag polar of investigated airfoils (XFOIL, $R e=2.2 \times 10^{5}$ ) previously used for EAV-1, and the others are known to be high-performance airfoils that are commonly used in small-scale UAVs, low-speed gliders, sailplanes, and humanpowered aircraft. SG6043, in particular, was originally designed for use in variable-speed wind turbines. ${ }^{9}$

The geometrical information and the aerodynamic characteristics of the investigated airfoils was calculated using XFOIL, as shown in Figs. 5 and Table 3, respectively. The Reynolds number based on the airfoil chord length is of about $R e=2.2 \times 10^{5}$. Fig. 5 suggests that SG6043, FX63-137, E61, and S1223 have a stall delay and maintain a maximum lift within the range of the drag increase. The amount of drag for SG6043, FX63-137, and E61 is relatively lower than that for S1223 and GOE15. In particular, SG6043 and FX63-137 produce the minimum drag over a wide range of lift that covers the target lift at cruise conditions $\left(0.8<c_{l}<1.5\right)$. Table 3 shows that the thickness ratios of SG6043, FX63-137 and S1223 are relatively high, and the camber that contributes to the increase in the maximum lift is largest for S1223. Of all airfoils, SD7032M shows the lowest drag due to its lower thickness and camber ratio, although its overall lift level is also the lowest. On the other hand, S1223 produces the highest lift and drag. Therefore, the lift to drag ratios, $\left(c_{l} / c_{d}\right)$ max of both airfoils are similar, as shown in Table 3. However, the levels of $\left(c_{l} / c_{d}\right)_{\max }$ for SG6043, FX63-137, and E61 are relatively high, and they have lower-drag levels at cruise lift coefficient, indicated as $c_{d @ c l=1}$. Also, the aerodynamic stall performance of these airfoils is favorable as a result of the higher $\alpha_{\text {stall }}$ and good stall delay characteristics, as previously mentioned. The manufacturing tolerance and geometrical distortion are important factors for the actual performance of the airfoils and wings. A tiny geometrical distortion of the airfoil caused by a manufacturing error can result in a significant reduction in its aerodynamic performance. A thin and high cambered shape for E61 may produce similar problems, and so this airfoil is not considered for use in EAV2 in spite of its excellent aerodynamic performance. The potential weight increase due to structural reinforcements

Table 3. Geometrical parameters and aerodynamic coefficients of investigated airfoils (XFOIL, $R e=2.2 \times 10^{5}$ )

\begin{tabular}{c|ccc|ccccc}
\hline \multirow{2}{*}{ Airfoil } & \multicolumn{3}{|c|}{ Geometrical parameters } & \multicolumn{5}{c}{ Aerodynamic coefficients } \\
\cline { 2 - 9 } & $\begin{array}{c}t_{\max } / C \\
(\%)\end{array}$ & $\begin{array}{c}R_{L E} / C \\
(\%)\end{array}$ & $\begin{array}{c}\text { Camber } \\
(\%)\end{array}$ & $\begin{array}{c}c_{l_{\alpha}} \\
\left(\mathrm{rad}^{-1}\right)\end{array}$ & $\begin{array}{c}c_{l_{\max }} \\
(\sim)\end{array}$ & $\begin{array}{c}\left(c_{l} / c_{d}\right)_{\max } \\
(\sim)\end{array}$ & $\begin{array}{c}c_{d @ c l=1} \\
(\sim)\end{array}$ & $\begin{array}{c}\alpha_{\text {stall }} \\
(\text { deg. })\end{array}$ \\
\hline SD7032M & 8.5 & 1.6 & 3.1 & 5.32 & 1.29 & 74.5 & 0.0145 & 11 \\
SG6043 & 10.0 & 1.7 & 5.5 & 6.31 & 1.65 & 97.6 & 0.0126 & 17 \\
FX63-137 & 13.7 & 2.2 & 5.8 & 5.98 & 1.73 & 90.8 & 0.0147 & 19 \\
S1223 & 12.1 & 3.1 & 8.7 & 6.89 & 2.22 & 73.2 & 0.0174 & 13 \\
E61 & 5.7 & 1.4 & 6.7 & 7.51 & 1.61 & 112.9 & 0.0143 & 10 \\
GOE15 & 9.0 & 3.5 & 7.8 & 5.65 & 1.70 & 70.6 & 0.0199 & 14 \\
\hline
\end{tabular}


for thin airfoils could be another disadvantage to the use of E61.

Figure 6 shows the aerodynamic performance of fullscale aircraft models equipped with SG6043 and FX63-137, which are airfoils that have a good stall delay characteristics and exhibit the least drag at cruise lift. Both airfoils were numerically implemented in an interim configuration of EAV-2 with a wing model of $A R=20$ and $S_{W}=2.0 \mathrm{~m}^{2}$. For comparison, the aircraft with SD7032M (EAV-1 airfoil) was also included in the analysis. The Reynolds numbers were of about $R e=2.8 \times 10^{5}$ according to the mean geometric-chord of the wing and a cruise speed of $V=12 \mathrm{~m} / \mathrm{s}$. The fan model for the propeller slipstream was omitted to simplify the simulations. The lift curve slopes in Fig. 6(a) suggests that SG6043 and FX63-137 produce a considerably higher lift force. The maximum lift of the SD7032M aircraft is $C_{L_{\max }}=1.3$ while those of the SG6043 and FX63-137 aircraft are of about $C_{L_{\max }}=1.7$, with an increase of about $30 \%$. However, SG6043 and FX63-137 exhibit no significant differences in terms of their lift characteristics. Fig. 6(b) indicates that the three aircraft produce similar amounts of drag (about $C_{D}=0.05$ ) at $C_{L}=0.8-1.0$. However, SG6043 and FX63-137 exhibit a relatively low drag at a higher lift range, until $C_{L}=1.4-1.6$ while the SD7032M aircraft stalls at $C_{L}=1.2$.

The XFOIL and CFD analyses suggest that both SG6043 and FX63-137 have excellent aerodynamic characteristics when applied to EAV-2. We finally select SG6043 with a thicker trailing edge as an optimal airfoil for EAV-2 since it offers potential advantages in terms of its manufacturability when compared to FX63-137. However, a transitionpoint sensitivity study showed that the drag level for both airfoils substantially increased under a forced transition condition. ${ }^{15}$

Therefore, the surface of the EAV-2 wings should be completely finished during manufacturing to prevent possible forced transitions from the solar cell installation.

\subsubsection{Wing aspect ratio}

The induced drag of a wing is well known to depend on the square root of the lift and is also inversely proportional to wing aspect ratio. Therefore, a high-lift airfoil, such as SG6043, is more susceptible to an increase in the induced drag. Furthermore, the induced drag becomes dominant in a low-speed regime. Therefore, the wing aspect ratio should be maximized in order to minimize the induced drag of a lowspeed aircraft.

The effect of the wing aspect ratio on the drag reduction was also computationally examined. Three wings with different aspect ratios of $A R=20,15.6$, and 12.5 were considered with the SG6043 airfoil. The wing area of $S_{W}=2.0 \mathrm{~m}^{2}$ and taper ratio were fixed, and the span and root chord length were changed to obtain three different aspect ratios, as shown in Table 4. The dihedral angle, $\Gamma=4^{\circ}$, is applied at a $65 \%$ spanwise station for all wings, and the equivalent dihedral angle that effects the lateral-directional stability was calculated as $\Gamma_{e q}=2.34^{\circ}$ for all three wings. ${ }^{16}$ We simulate the wing parts by only using the symmetry boundary condition, and the total mesh cell size is of about 2.66 million. The Reynolds number based for the wing with $A R=20$ is $R e=2.8 \times 10^{5}$.

Figure $7(\mathrm{a})$ shows the effect of the aspect ratio on the drag polars. As $A R$ increases at the same lift level, the drag reduction becomes significant. The total drag for wings with $A R=12.6,15.6$ and 20 is calculated as $\mathrm{C}_{D @ C L=1}=0.0486,0.0448$, and 0.0400 , respectively. Therefore, the total drag of the wing decreases by $18 \%$ with a $59 \%$ increase in the aspect ratio. This is mainly a result of the reduction in the tip vortex strength that decreases the level of the induced drag. Fig. 7(b) presents the simulated trailing tip vortex at the free steam region with $30 \%$ of the tip chord length after the trailing edge of each wing. The figure indicates that a wing with a higher aspect ratio induces a weaker tip vortex, as shown by the smaller swirling flow area and lower vorticity magnitude. Therefore, $A R=20$ was determined as the appropriate aspect ratio for the EAV-

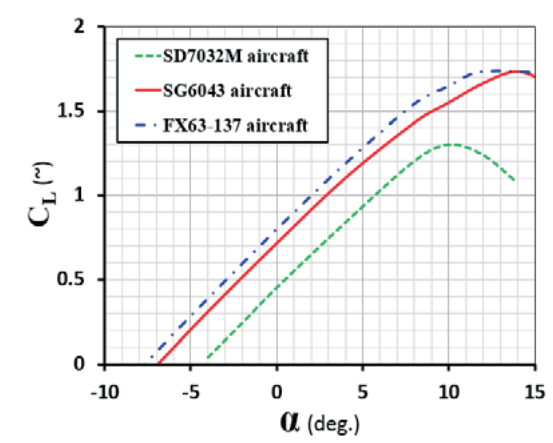

(a) Lift curve slop

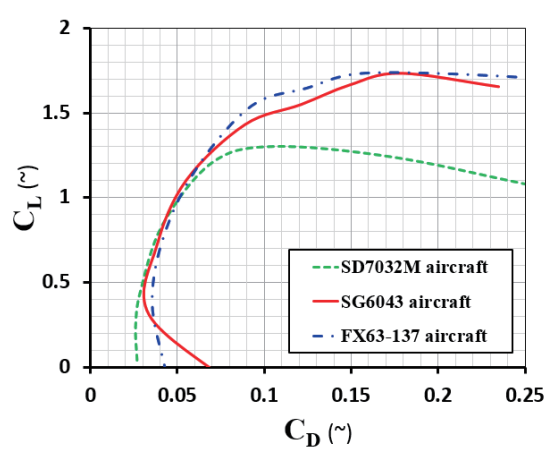

(b) Drag polar

Fig. 6. Aerodynamic characteristics of full-scale aircraft models with different airfoils (FLUENT, $R e=2.8 \times 10^{5}$ ) 


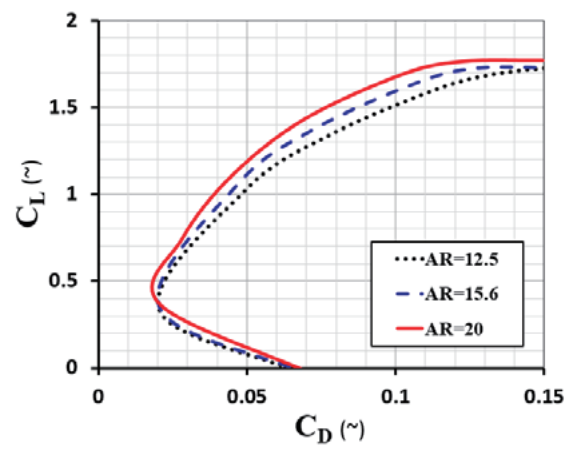

(a) Drag polar

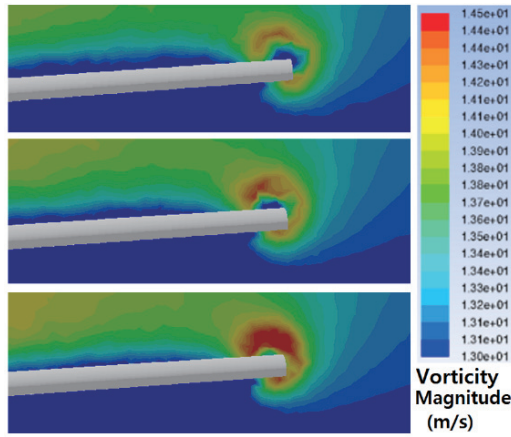

(b) simulated tip vortex strength $\left(a=8^{\circ}\right)$

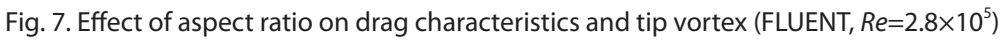

2 wings. Wings with a high aspect ratio over $A R=20$ are not considered since an excessive wing deformation due to a high aspect ratio causes additional aerodynamic penalties and can increase the weight due to the structural reinforcement.

\subsubsection{Raked wingtip}

Wingtip devices, such as tip extensions and winglets, have also been applied to aircraft to minimize the induced drag. Vertical winglets have been experimentally proven to be aerodynamically superior over tip extension. ${ }^{17}$ However, vertical winglets has a disadvantage for use with EAV-2 in that the shadow of the vertical winglet would partially reduce the amount of electricity generated by the solar cells on the wings during flight. A raked wingtip is known to be one of the most efficient tip-extension shapes. The Boeing B777 airplane benefits from an improvement in fuel efficiency of $2 \%$ when raked wingtips are installed..$^{18}$ It also reduces wing weight when compared to a vertical winglet. A computational study showed that a raked wingtip induced a weaker trailing vortex than other wingtip devices, both in the flow- and spanwise-directions, ${ }^{19}$ and the dissipation length of the vortex was also noticeably shortened when the raked wingtip was used.

The raked wingtip is considered for the wing with an $A R=20$ for EAV-2 with an arc-shaped leading edge with a higher sweep angle in order to prevent the over-extension of the wing span, as shown in Fig. 8. Fig. 9(a) shows that the raked wingtip reduces the strength of the tip vortex in the wake region. The drag polar comparison in Fig. 9(b) indicates that the induced drag decreases under the effect of the raked wingtip. At a cruise lift coefficient, the drag coefficients when clean and raked wingtips are used are $\mathrm{C}_{D @ C L=1}=0.0409$ and 0.0395 , respectively, with a reduction of about $3.4 \%$. Therefore, the shape of the raked wingtip was applied to the

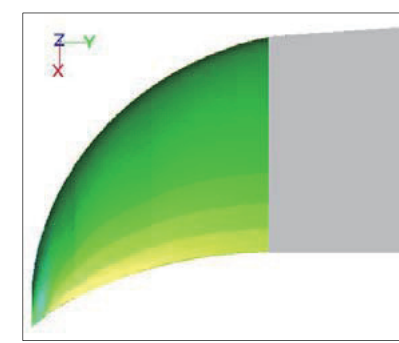

Fig. 8. Geometry of EAV-2 raked wingtip

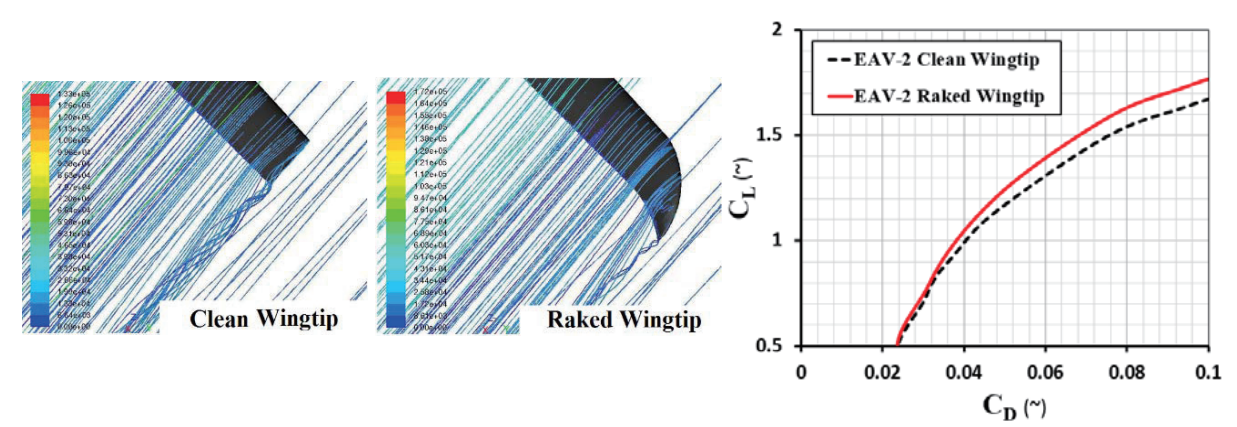

(a) Comparison of tailing tip vortices

(b) Drag polar

Fig. 9. Effect of EAV-2 raked wingtip (FLUENT, Re=2.8 $\times 10^{5}$ ) 
Table 4. Geometrical parameters of wing planforms with different aspect ratios

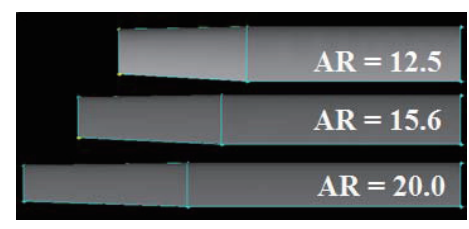

\begin{tabular}{c|cccccc}
\hline $\begin{array}{c}A R \\
(\sim)\end{array}$ & $\begin{array}{c}S_{W} \\
\left(\mathrm{~m}^{2}\right)\end{array}$ & $\begin{array}{c}b_{W} \\
(\mathrm{~m})\end{array}$ & $\begin{array}{c}C_{r} \\
(\mathrm{~m})\end{array}$ & $\begin{array}{c}\lambda \\
(\sim)\end{array}$ & $\begin{array}{c}\Gamma \\
(\mathrm{deg} .)\end{array}$ & $\begin{array}{c}\Gamma_{e q} \\
(\mathrm{deg} .)\end{array}$ \\
\hline 12.5 & 19.8 & 5.0 & 0.40 & 0.82 & 4.0 & 2.34 \\
15.6 & 19.8 & 5.6 & 0.36 & 0.82 & 4.0 & 2.34 \\
20.0 & 19.8 & 6.4 & 0.32 & 0.82 & 4.0 & 2.34 \\
\hline
\end{tabular}

$A R=20$ wings for EAV-2 to further minimize the induced drag in long-endurance flights.

\subsection{Evaluation of the fuselage configuration}

The EAV-2 fuselage should provide sufficient room for onboard equipment. Fig. 10 shows the electric power system and the onboard mission equipment, including the motor, fuel-cell packages, power management system (PMS), and flight control computer (FCC). However, minimizing the fuselage drag is also important since the fuselage counts for almost $10 \%$ of the total drag, as shown in Table 1. It is possible for the effective design of the internal equipment layout and fuselage configuration to reduce the drag profile as a result of the reduction in volumetric size and streamlined shape. The design history of EAV2 is presented in Table 5. Basically, T-tails are commonly considered for the all configurations. A T-tail type stabilizer has the advantage that it increases the stabilization in the

Table 5. Studied configurations for EAV-2

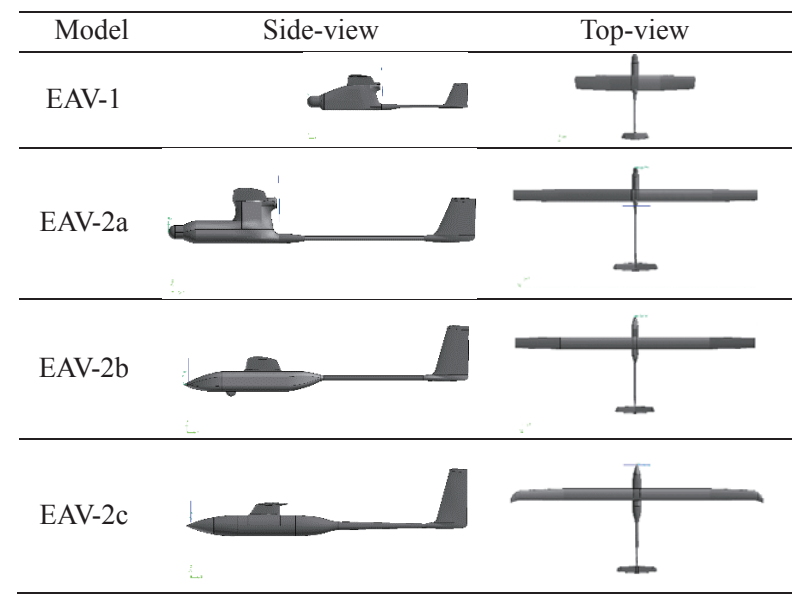

low-speed regime. EAV-2a is the first design considered with an upsized configuration of EAV-1. This pusher-type configuration is mainly characterized by a semi-spherical nose that is included as a mount for a surveillance system with a part that is perpendicular to the airflow between the fuselage and the wing. The pusher-type has usually not streamlined configuration causing more profile drag, in spite of an aerodynamic advantage; the airflow attachment over the wing and fuselage, reducing the chance of flow separation. However, the reduction in the propeller efficiency is another crucial disadvantage. This configuration has therefore been modified into a tractortype system named EAV-2b. The tractor-type layout makes it possible for us to design a streamlined-fuselage shape, resulting in a considerable reduction in the drag profile. In addition, the cross-sectional shape of the fuselage is rectangular in order to accommodate the fuel cell system of a parallelepiped configuration. The overall length and the horizontal stabilizer area decrease by $5 \%$ and $20 \%$, respectively, and the vertical stabilizer area increases by $25 \%$ to improve the longitudinal and lateral-directional stability. ${ }^{15}$ The final EAV-2c design has the following modifications: first, the rectangular cross-section of the parallelepiped fuselage shape of EAV-2b was changed into a circular shape, which offers a reduction in the possible flow separation from the corners of the rectangular cross-section at high angles of attack. However, the cross-sectional area increases somewhat relative to the rectangular fuselage of EAV-2b. Second, the sweep angle of the wing trailing edge is now applied to the leading edge, maintaining the same taper ratio. This design change in the wing planform increases the aileron efficiency by increasing the aileron area. Third, we also increase the aspect ratio of the vertical stabilizer based on the constant area to enhance the T-tail

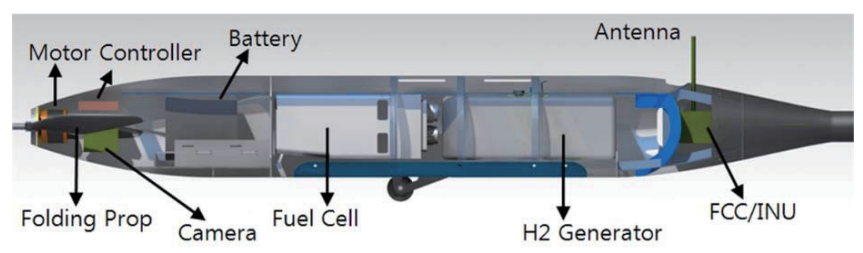

Fig. 10. Power system and onboard mission equipment inside EAV-2 fuselage 


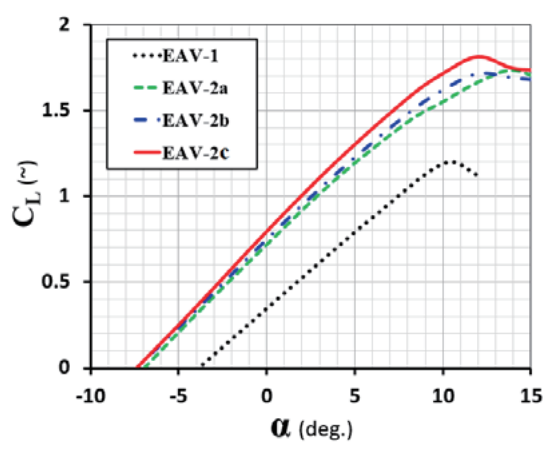

(a) Lift curve slop

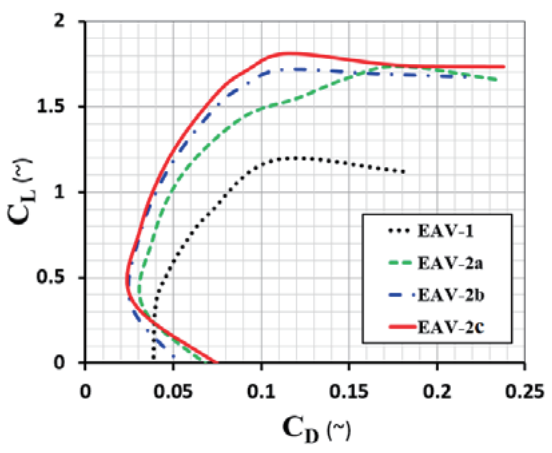

(b) Drag polar

Fig. 11. Aerodynamic characteristics of studied configurations for EAV-2 (FLUENT, Re $=2.8 \times 10^{5}$ )

efficiency. Finally, raked wingtips are installed to reduce drag, as shown in Table 5.

Figure 11 presents the results of the CFD analysis of the aerodynamic performance of the different EAV-2 configurations. A fan model is incorporated into the analysis to simulate the effect of the propeller slipstream. The lift curve slopes in Fig. 11(a) indicate that the lift performance for EAV-2 considerably improved relative to that of EAV-1, mainly due to the increase in the wing area and the adoption of a high lift-to-drag ratio airfoil with SG6043. EAV-2a, EAV$2 \mathrm{~b}$, and EAV-2c present similar lift characteristics when the SG6043 airfoil is used with the same aspect ratio $(A R=20)$. The difference in $C_{L_{\max }}$ and $\alpha_{\text {stall }}$ is caused by differences in the fuselage configuration and in the empennage size. In particular, EAV-2c with the raked wingtips produces the highest $C_{L_{\max }}$.

Figure 11(b) indicates the drag polars of different aircraft configurations. We can see from the figure that the smaller wings with a low-aspect ratio and un-streamlined fuselage of EAV-1 contribute to the higher drag at a wide range of lift. In contrast to EAV-1, the other aircraft with an improved airfoil and high-aspect ratio wings display a considerably smaller total drag. Of these, EAV-2a with a blunt nose and an un-streamlined fuselage configuration produces the highest total drag. However, we can see that the circular crosssectional fuselage and raked wingtips of EAV-2c contribute to generating the least amount of drag. The aerodynamic coefficients of the configurations that were studied are listed in Table 6. The maximum lift for EAV-2 is $C_{L_{\max }}=1.8$, and an increase of about $52 \%$ was achieved relative to EAV-1. Also, the drag coefficient for EAV-1 at the target cruise lift is of $C_{D @}$
$C L=1=0.0855$. For EAV-2a, the upsized version of EAV-1, the drag is $C_{D @ C L=1}=0.0505$, which is a decrease of about $41 \%$ relative to EAV-1. The drag level is further decreased to $C_{D @ C L=1}=0.0413$ for EAV-2b with the low-drag fuselage. The drag generated by EAV-2c is $C_{D @ C L=1}=0.0395$, and the drag reduction from EAV-1 is of up to $54 \%$. Therefore, the last configuration, EAV-2c, is selected as the final configuration for EAV-2.

\subsection{Installation of the NACA duct inlets}

The fuel cells installed in the EAV-2 fuselage require $850 \mathrm{l} /$ min of air to produce the chemical reaction of the oxidant. Also, cooled air is necessary for the power systems and the onboard mission equipment. Therefore, the EAV-2 fuselage must have inlets or air-scoops through which outside air can be provided to the fuel cell systems and onboard equipment. However, the inlet installation produces a large amount of fuselage drag. We considered NACA duct inlets since they possess the following aerodynamic advantages. First, they are submerged in the fuselage, therefore, flow separation can be minimized. Second, a gentle inclination for the ramp and vortex generation from a convergent-divergent shape

Table 6. Aerodynamic coefficients of studied configurations for EAV-2 (FLUENT, $R e=2.8 \times 10^{5}$ )

\begin{tabular}{|c|c|c|c|c|}
\hline Coeff. & EAV-1 & EAV-2a & EAV-2b & EAV-2c \\
\hline$C_{L_{\max }}$ & $\begin{array}{c}1.188 \\
\text { (a) } \alpha=10^{\circ}\end{array}$ & $\begin{array}{c}1.735 \\
(a)=14^{\circ}\end{array}$ & $\begin{array}{c}1.714 \\
(a)=12^{\circ}\end{array}$ & $\begin{array}{c}1.811 \\
(a), \alpha=12^{\circ}\end{array}$ \\
\hline$C_{L \alpha}\left(\operatorname{rad}^{-1}\right)$ & 5.04 & 4.77 & 4.98 & 5.55 \\
\hline$C_{D_{\min }}$ & 0.0388 & 0.0336 & 0.0258 & 0.0270 \\
\hline$C_{D} @ C L=1$ & 0.0855 & 0.0505 & 0.0413 & 0.0395 \\
\hline
\end{tabular}

Table 7. Coordinates of convergent-divergent ramp for EAV-2 NACA duct inlet

\begin{tabular}{c|ccccccccccc}
\hline$x / l_{r}$ & 0.0 & 0.1 & 0.2 & 0.3 & 0.4 & 0.5 & 0.6 & 0.7 & 0.8 & 0.9 & 1.0 \\
\hline $2 y / W$ & 1.000 & 0.996 & 0.916 & 0.766 & 0.614 & 0.466 & 0.388 & 0.312 & 0.236 & 0.158 & 0.085 \\
\hline
\end{tabular}


of a NACA duct inlet would suppress the development of a boundary layer, ${ }^{20}$ and the total pressure recovery can be maximized. To determine the size of the NACA inlets, the conditions for the full mass-flow and the maximum efficiency were respectively considered.

The cross-sectional size of the NACA inlet, $\mathrm{A}=0.003 \mathrm{~m}^{2}$, is conservatively adjusted according to the boundary layer thicknesses calculated from the CFD analysis for different angles of attack (Fig. 12). The $\mathrm{x}$ - and $\mathrm{y}$-coordinates ${ }^{20}$ that are defined for the curved-divergent ramp section of the NACA duct inlet for EAV-2 are presented in Table 7. The width and depth of the inlet section are $W=0.11 \mathrm{~m}$ and $d_{t}=0.0273 \mathrm{~m}$ (Fig. 13), respectively, with an aspect ratio of $W / d_{t}=4$. The ramp angle is defined as $7^{\circ}$, and the length of the curved-divergent section of the NACA duct inlet is of $l_{r}=0.22 \mathrm{~m}$. The total drag of the two NACA duct inlets on both sides of the fuselage is estimated to be $C_{D}=0.0045$ using the empirical formula for inlet drag coefficients. ${ }^{20}$ This drag component should be added to the previously obtained total drag of EAV-2, $\mathrm{CD}=0.0395$. Therefore, the total drag coefficients for EAV-2 with the installation of the NACA duct inlets is of $C_{D}=0.0440$. In addition, the inlet pressure efficiency is calculated to be about $\eta_{\text {inlet }}=0.85$ according to the condition of maximum efficiency.

\subsection{Static stability analysis}

The static stability characteristics of the final EAV-2c configuration are tested under steady flight conditions,

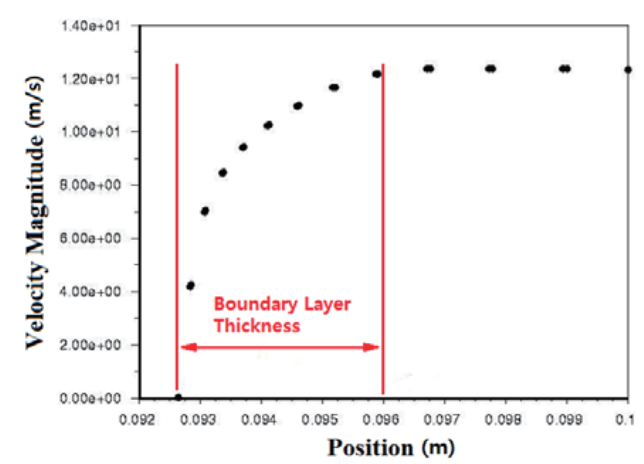

Fig. 12. Example of calculation of boundary layer thickness on EAV-2 fuselage (FLUENT, $R e=2.8 \times 10^{5}$ ) and we generate the derivatives for longitudinal and lateral stability using the AAA software. ${ }^{14}$ The flight speed and the altitude are set to $V=12 \mathrm{~m} / \mathrm{s}$ and $h=500 \mathrm{~m}$ based on the flight test. Also, the location of c.g. is assumed to be at $25 \%$ of MAC, and no deflection angle is considered for all control surfaces $\left(\delta_{e}=\delta_{a}=\delta_{r}=0^{\circ}\right)$.

Tables 8 provides the longitudinal stability derivatives of EAV-2, and the derivatives of EAV-1 for the same flight condition are also presented for comparison. An inspection of the $+/$ - sign of the longitudinal derivatives is fundamental to verify the static longitudinal stability. The pitching moment of the aircraft should be negative with an increase in the angle of attack or pitch rate. The negative numbers for the derivatives in Table 8 indicate that the longitudinal static stability is basically secured for EAV2. However, the tendency for the nose-down behavior of EAV-2 with the increase in the angle of attack is somewhat excessive, considering the fact that the pitching moments of conventional aircraft are $-0.6<C_{m_{\alpha}}<-1.6 \mathrm{rad}^{-1}{ }^{21}$ The derivatives of the lateral stability at a zero angle of attack are shown in Table 9. A comparison of the signs of the calculated derivatives and the stable criteria ${ }^{14}$ suggests that the lateral and directional static stabilities could be achieved for EAV-2. In general, $C_{l_{\beta}}$, is significantly affected by the dihedral angle of the aircraft wing. A negative sign for $C_{l_{\beta}}$ indicates that during a steady sideslip, EAV-2 maintains lateral stability due to the effect of a dihedral angle of $\Gamma=4^{\circ}$ that induces a rolling moment in the opposite direction. Also, for the directional stability, typical aircraft should have values of $C_{n_{\beta}}$ over $0.0573 \mathrm{rad}^{-1,21}$ and $C_{n_{\beta}}$ of EAV-2 is turn out to be $0.074 \mathrm{rad}^{-1}$. Therefore, we can see that a $25 \%$ increase in the vertical stabilizer area for EAV-2, as mentioned in Chapter 3.2, improves the static directional stability.

Table 8. Longitudinal stability derivatives by $\mathrm{AAA}^{14}$ (c.g. $=25 \% \mathrm{MAC}$, $\delta_{\mathrm{e}}=\delta_{\mathrm{a}}=\delta_{\mathrm{r}}=0^{\circ}$, unit: $\mathrm{rad}^{-1}$ )

\begin{tabular}{cccc}
\hline Derivates & EAV-1 & EAV-2 & $\begin{array}{c}\text { Stable } \\
\text { Criteria }^{14}\end{array}$ \\
\hline$C_{m_{\alpha}}$ & -0.670 & -2.981 & $<0$ \\
$C_{m_{\dot{\alpha}}}$ & -3.441 & -4.255 & $<0$ \\
$C_{m_{q}}$ & -13.204 & -36.597 & $<0$ \\
\hline
\end{tabular}
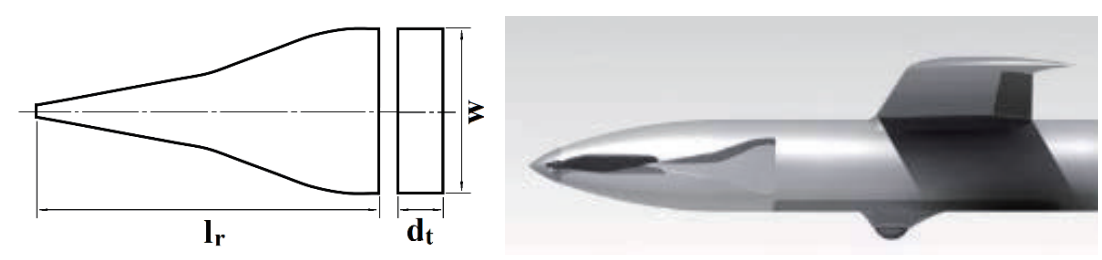

Fig. 13. NACA duct inlet for EAV-2 
Table 9. Lateral-directional stability derivatives by AAA $\left(\alpha=0^{\circ}\right.$, $\delta_{\mathrm{e}}=\delta_{\mathrm{a}}=\delta_{\mathrm{r}}=0^{\circ}$, unit: $\mathrm{rad}^{-1}$ )

\begin{tabular}{cccc}
\hline Derivates & EAV-1 & EAV-2 & $\begin{array}{c}\text { Stable } \\
\text { Criteria }^{14}\end{array}$ \\
\hline$C_{y_{\beta}}$ & -0.143 & -0.236 & $<0$ \\
$C_{y_{p}}$ & -0.103 & -0.041 & $<0$ \\
$C_{y_{r}}$ & 0.098 & 0.144 & $>0$ \\
$C_{l_{\beta}}$ & -0.282 & -0.117 & $<0$ \\
$C_{l_{p}}$ & -0.439 & -0.557 & $<<0$ \\
$C_{l_{r}}$ & 0.139 & 0.256 & $>0$ \\
$C_{n_{\beta}}$ & 0.033 & 0.074 & $>0$ \\
$C_{n_{p}}$ & -0.057 & -0.121 & $<0$ \\
$C_{n_{r}}$ & -0.048 & -0.073 & $<0$ \\
\hline
\end{tabular}

\subsection{Long endurance flight test}

Figure 14 and Table 10 show the final configuration of EAV-2 based on EAV-2c and its performance objectives to achieve a long-endurance flight. A cruise power of less than 200 Watts is defined due to the expected performance

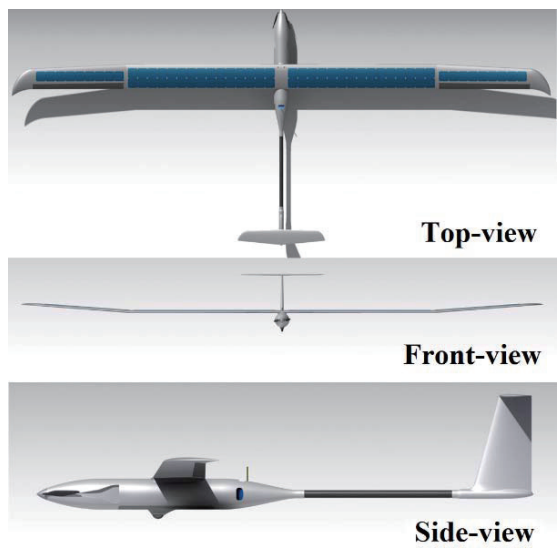

Fig. 14. The final configuration of EAV-2 of a hybrid power system. This power level can be achieved since the cruise power has been estimated at $P=165$ watt by taking the results of the CFD analysis and propeller wind tunnel tests ${ }^{22}$ and applying them to the following equation:

$$
\begin{aligned}
& \begin{array}{l}
T V=\eta_{\text {prop }} \eta_{\text {motor }} P \\
P=T V /\left(\eta_{\text {prop }} \eta_{\text {motor }}\right)=D V /\left(\eta_{\text {prop }} \eta_{\text {motor }}\right) \\
\quad=C \_D \frac{1}{2} \rho V^{3} S w /\left(\eta_{\text {prop }} \eta_{\text {motor }}\right) \\
\quad=165 \text { watt }
\end{array} \\
& \text { Where, } C_{D}=0.0440, \eta_{\text {prop }}=0.66,{ }^{22} \eta_{\text {motor }}=0.85,{ }^{22} \\
& \rho=1.167 \mathrm{~kg} / \mathrm{m}^{3} \text { at } h=500 \mathrm{~m}, V=12 \mathrm{~m} / \mathrm{s}, S_{W}=2.09 \mathrm{~m}^{2}
\end{aligned}
$$

The final configuration was used to build EAV-2 for the flight test. Special care was taken to install solar cells on the EAV-2 wings to prevent gaps or rough surfaces that could cause additional drag due to the possible transition to turbulence or flow separation. A long-endurance test flight was conducted for EAV-2 at the KARI Goheung Aviation Center, Korea. The main objective of the test was to fly more than 20 hours while consuming less than 200 Watts from the hybrid power system consisting of fuel cells and solar cells. The flight test for EAV-2 turned out to be successful, flying 22 hours and 13 minutes, which is the flight record for electrically powered aircraft in Korea. The flight speed was of about $V=43 \mathrm{~km} / \mathrm{hr}(11.9 \mathrm{~m} / \mathrm{s})$ at an altitude of $h=500 \mathrm{~m}$. The flight that was actually carried out was a steady-level turning flight over the Goheung Aviation Center rather than a steady-level flight. However, we increased the turn radius up to $1 \mathrm{~km}$ to simulate steady-level flight to minimize the use of deflection of the control surfaces.

The total drag of the aircraft can be estimated by measuring the in-flight thrust. However, it was difficult to measure the thrust force for EAV-2 during the actual test flight. Therefore, we used performance data for the EAV2 propeller ${ }^{22}$ acquired from the Low Speed Wind Tunnel at KARI. The data of the propeller performance includes

Table 10. Final geometry and performance objectives of EAV-2

\begin{tabular}{ll|ll}
\hline Item & Specification & Item & Specification \\
\hline Chord & $0.32 \mathrm{~m}$ & Wing aspect ratio & 20 \\
\multirow{2}{*}{ Span } & $6.40 \mathrm{~m}$ & & 23 \\
& $6.93 \mathrm{~m}$ & & (w/ raked wingtip) \\
& $(\mathrm{w} /$ raked wingtip) & Max. T/O weight & $18.0 \mathrm{~kg}$ \\
Length & $3.06 \mathrm{~m}$ & Stall speed & $9.8 \mathrm{~m} / \mathrm{s}$ \\
Height & $0.77 \mathrm{~m}$ & Cruise speed & $12.0 \mathrm{~m} / \mathrm{s}$ \\
Wing area & $1.98 \mathrm{~m}^{2}$ & Cruise power & $<200$ watt \\
& $2.09 \mathrm{~m}^{2}$ & Endurance & $>20$ hours \\
& $(\mathrm{w} /$ raked wingtip $)$ & & \\
\hline
\end{tabular}




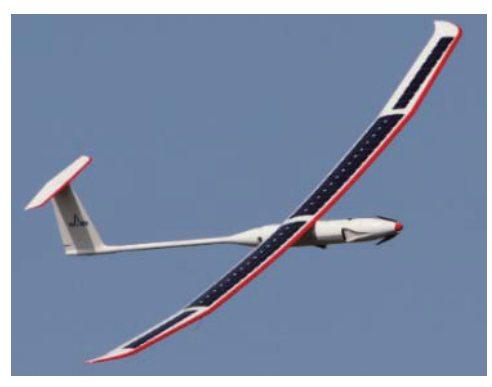

Fig. 15. Flight speed of EAV-2

thrust coefficients, power coefficients, and propeller efficiencies with respect to the advance ratios. The range of the thrust of the EAV-2 in flight was obtained from the propeller performance data corresponding to the flight test conditions. The air density was also calculated by using the International Standard Atmosphere (ISA) model and the flight altitude. The time history of flight speed was measured directly using the on-board pitot-static tube of EAV-2, as shown in Fig. 15. In particular, the flight speed was calibrated by using the airspeed calibration data from the wind tunnel tests. Fig. 16 shows the curve fitting for the calibrated airspeed (CAS) as a function of the indicated airspeed (IAS), as measured by the Ground Control System (GCS). In addition, Fig. 17 presents the time history of the

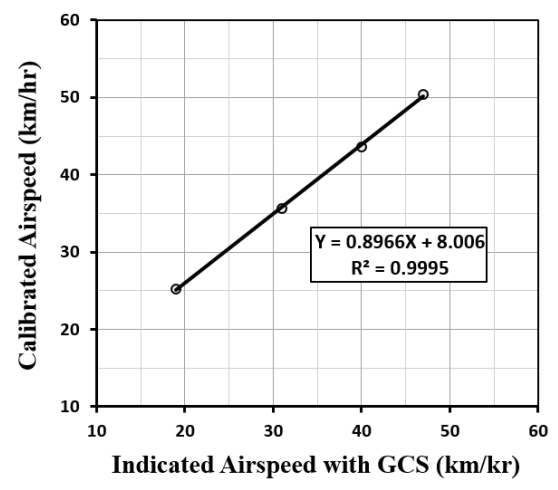

Fig. 16. Curve fitting calibrated airspeed vs. indicated airspeed

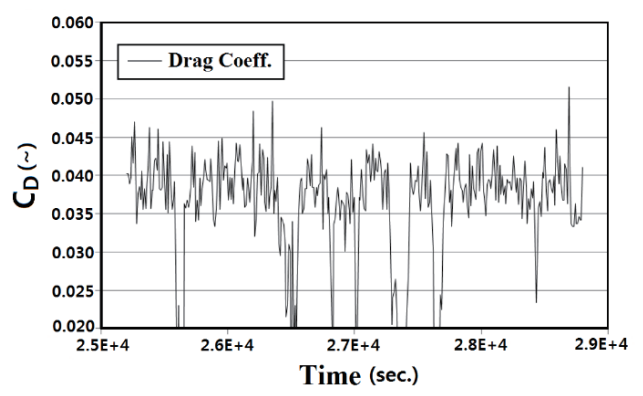

Fig. 17. Time history of in-flight drag coefficient of EAV-2

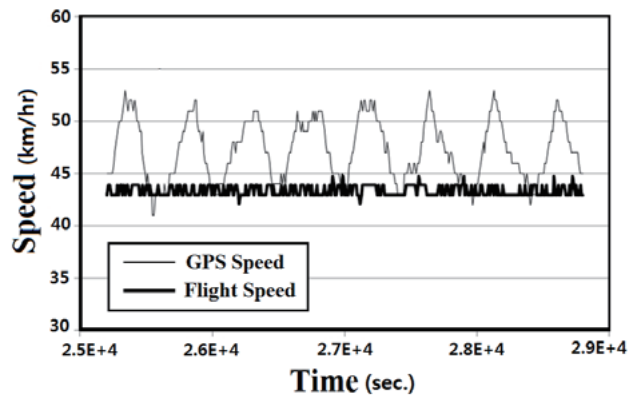

total drag coefficient for EAV-2 according to the flight test measurements calibrated using the wind tunnel data. The time-independent drag coefficient was calculated from the time history by averaging the drag values in the time range of the least variation, at around 26,000 sec. Therefore, we obtained the total drag coefficient of $C_{D}=0.0390$ from the actual flight test of EAV-2. When compared to the total drag coefficient of $C_{D}=0.0440$ obtained from the computational analysis, the discrepancy was of about $13 \%$. As shown in Fig. 18, the average power consumption during the flight test was of approximately 150 Watts, which is less than the objective cruise power of 200 Watts. Therefore, the design procedure that was investigated in this study to reduce the drag is confirmed to be effective for long-endurance flights of EAV-2.

\section{Conclusion}

The present study conducted a computational investigation of the low-drag configurations for a longendurance mission for EAV-2, an electric-powered UAV that was developed at KARI. Considering that the wings of long-endurance aircraft generate most of the aircraft drag, a reduction in drag can be achieved by focusing on optimizing the wing configuration parameters, such as the

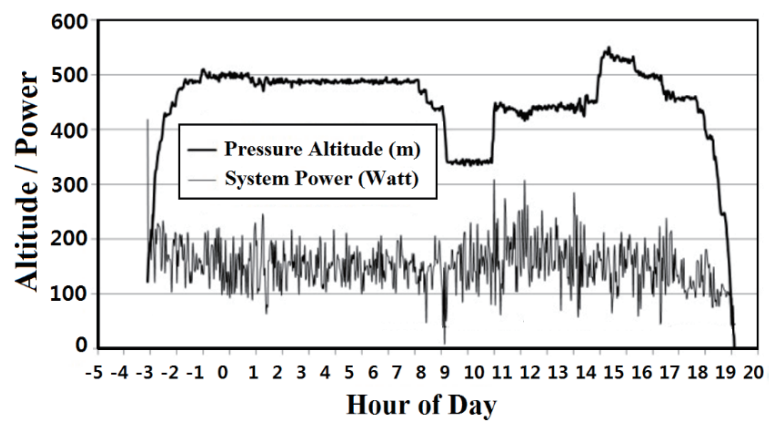

Fig. 18. Flight altitude and power measurement of EAV-2 
airfoil shape, aspect ratio, and wingtip device. The results of the computational analysis revealed that SG6043 was the most suitable low-drag airfoil for EAV-2 since it possesses favorable stall characteristics and better manufacturability. The study of the wing aspect ratio conformed the aerodynamic benefit of a high aspect-ratio wing; total drag of the $A R=20$ wing was $18 \%$ lower than that of the $A R=12.5$ wing, due to the substantial decrease of the induced drag. Therefore, $A R=20$, the aspect ratio of compromising between aerodynamic and structural advantages, was considered for the EAV-2 wings. The installation of the raked wingtip contributed to the additional decrease of total drag by $3.4 \%$, and the computational visualization of the weakened tip-vortex from the raked wingtip proved the reduction in the induced drag.

The aerodynamic characteristics of several fuselage configurations were analyzed for EAV-2. The first configuration was a pusher type, and it turned out to be aerodynamically inefficient due to its un-streamlined fuselage shape and relative inefficiency at the propeller. Therefore, the fuselage layout was changed to a streamlined tractor-type layout with a rectangular cross-section, which was eventually modified to a circular cross-section to reduce the drag further. The total drag of the final configuration of the EAV-2 with a low-drag airfoil, high-aspect ratio wing, raked wingtip, and tractor-type fuselage was calculated to be $C_{D}=0.0395$ at a cruise lift of $C_{L}=1.0$. The effect of these low-drag modifications was significant since the drag level of its small-sized predecessor, EAV-1, was $C_{D}=0.0855$. The lift performance also improved since the maximum lift of EAV-2 was $C_{L_{\max }}=1.8$, which was $52 \%$ higher than that of EAV-1. The installation of the inlets increased the total drag of EAV-2 up to $\mathrm{CD}=0.0440$. However, this increase could be minimized by using aerodynamically designed NACA duct inlets.

The static stability performance of the final EAV-2 configuration was also evaluated before the flight test. The longitudinal derivatives were inspected using aircraft design software, and these suggested that the longitudinal static stability was basically achievable. However, the nosedown tendency with respect to the increase in the angle of attack was slightly excessive. In addition, the final layout and the size of the aircraft components were confirmed to have maintained the lateral and directional static stabilities. The effort to minimize the drag of EAV-2 was verified by conducting a long-endurance flight test. The actual power consumption was of about 150 watt, which was much lower than the design objective power of 200 watt, and the in-flight total drag was measured as $C_{D}=0.0390$, which was also less than the total drag predicted at $C_{D}=0.0440$.

\section{Acknowledgement}

This research was supported by the Korea Aerospace Research Institute (KARI) under the "System and Operational Technology Research for Electric Airplane (II)” project.

\section{References}

[1] FAI Record ID No. 16052, Fédération Aéronautique Internationale.

[2] R. Laurenzo, "Soaring on a Solar Impulse," Aerospace America, Vol. 47, No. 5, 2009, pp. 32-36.

[3] B. H. Lee, P. M. Park, K. B. Kim, and B. J. Cha, "A Study on Optimum Takeoff Time of the Hybrid Electric Powered Systems for a Middle Size UAV," Journal of The Korean Society Aeronautical and Space Sciences, Vol. 40, No. 11, 2012, pp. 940-947.

[4] P. M. Park, K. B. Kim, and B. J. Cha, "Flight Test of Hybrid Propulsion System for Electrically Powered UAV," Journal of the Korean Society of Propulsion Engineers, Vol. 17, No. 4, 2013, pp. 49-55.

[5] W. J. Jin, Y. G. Lee, C. W. Kim, S. M. Ahn, and D. S. Lee, "Computational Analysis of Aerodynamic Performance of a small-scale Electric Aerial Vehicle," Proceeding of the 2010 Korean Society for Aeronautical \& Space Sciences (KSAS) Fall Conference, Vol. 1, 2010, pp. 473-476.

[6] Y. G. Lee, W. J. Jin, S. M. Ahn, and D. S. Lee, "Numerical and In-Flight Drag Estimation of a Small Electric Aerial Vehicle," Proceeding of the 2011 Korean Society for Aeronautical \& Space Sciences (KSAS) Spring Conference, Vol. 1, 2011, pp. 839-844.

[7] M. Drela, and H. Youngren, XFOIL 6.94 User Guide, Massachusetts Institute of Technology, Cambridge, MA, URL: http://web.mit.edu/drela/Public/web/xfoil/, 2001.

[8] M. S. Selig, J. J. Guglielmo, A. P. Broeren, and P. Giguère, Summary of Low-Speed Airfoil Data, Vol. 1, Soar Tech Publications, Virginia Beach, 1995.

[9] C. A. Lyon, A. P. Broeren, P. Giguère, A. Gopalarathnam, and M. S. Selig, Summary of Low-Speed Airfoil Data, Vol. 3, Soar Tech Publications, Virginia Beach, 1998.

[10] ANSYS FLUENT Ver. 12 Software Package, Ansys Fluent Inc., Canonsburg, PA, USA.

[11] GAMBIT Software Package, Ver. 2.4.6, Ansys Fluent Inc., Canonsburg, PA, USA.

[12] TGRID Ver. 3.5, Ansys Fluent Inc., Canonsburg, PA, USA.

[13] G. W. Stickle, and J. L. Crigler, Propeller Analysis from Experimental Data, NACA Technical Report-712, 1941.

[14] Advanced Aircraft Analysis Software Package, Ver. 3.2, 
DARCorporation, Lawrence, KS, USA.

[15] W. J. Jin, and Y. G. Lee, "Computational Analysis of the Aerodynamic Performance of a Long-Endurance UAV," International Journal of Aeronautical and Space Sciences, Vol. 14, No. 4, 2014, pp. 374-382.

[16] www.charlesriverrc.org/articles/design/edal.xls

[17] H. H. Heyson, G. D. Riebe, and C. L. Fulton, Theoretical Parametric Study of the Relative Advantages of Winglets and Wing-tip Extension, NASA Technical Paper, 1977.

[18] http://boeing.mediaroom.com/2002-10-01-New-Boeing -777-Raked-Wing-Tips-Improve-Fuel-Efficiency-Good-forthe-Environment.

[19] R. Babigian, and S. Hayashibara, "Computational
Study of the Vortex Wake Generated by a Three-Dimensional Wing with Dihedral, Taper, and Sweep," AIAA Paper 20094107, Jun. 2009.

[20] "Drag and Pressure Recovery Characteristics of Auxiliary Inlets at Subsonic Speeds," ESDU International PLC, London, UK, 1986.

[21] D. P. Raymer, Aircraft Design: A Conceptual Approach, the 4th edition, AIAA Education Series, AIAA Inc., Reston, 2006.

[22] P. M. Park, O. S. Hwang, Y. M. Kim, C. T. Kim, and K. J. Kwon, "Wind Tunnel Test on Propellers for Middle Size Electric Propulsion UAV," Proceeding of the 2011 Korean Society of Propulsion Engineers (KSPE) Fall Conference, Vol. 1, 2011, pp. 784-788. 